\title{
ENTERAL/ORAL GLUTAMINE SUPPLEMENTATION IN PATIENTS FOLLOWING SURGERY AND ACCIDENTAL INJURY
}

\author{
VIJEY AANANDHI M ${ }^{1 *}$, MEHA RACHEL JOHN ${ }^{2}$ \\ ${ }^{1}$ Department of Pharmaceutical Chemistry and Analysis, School of Pharmaceutical Sciences, Vels University (VISTAS), Chennai - 600 117, \\ Tamil Nadu, India. ${ }^{2}$ Department of Pharmacy Practice, School of Pharmaceutical Sciences, Vels University (VISTAS), Chennai - 600 117, \\ Tamil Nadu, India. Email: hodpchemistry@velsuniv.ac.in \\ Received: 12 December 2016, Revised and Accepted: 26 December 2016
}

ABSTRACT

Objective: The objective of this investigation was to study the effect of enteral/oral glutamine supplementation in patients following abdominal surgery on plasma glutamine levels, rate of infection, and length of hospitalization (LOH).

Methods: A randomized control trial was used, and the patients were randomly divided into two groups, namely experimental and control with 30 participants each. Glutamine supplement $(0.5 \mathrm{~g} / \mathrm{kg})$ was administered (oral and enteral) to the experimental group for 5 days post-surgery immediately after the feeding began. The study was conducted in ESIC hospital, Chennai, India.

Results: The incidence of infection in the control group was found to be almost twice that in the experimental group considering the role of glutamine in combating infection. Furthermore, the LOH was found to be slightly higher in the control group as compared to the experimental group.

Conclusion: This study has provided evidence that the supplementation of enteral glutamine in post-operative patients decreases the incidence of post-surgical infection, shortening of hospital stay and reduction in the overall hospital costs.

Keywords: Glutamine supplementation, Post-operative patients, Oral and enteral feed.

(c) 2017 The Authors. Published by Innovare Academic Sciences Pvt Ltd. This is an open access article under the CC BY license (http://creativecommons. org/licenses/by/4.0/) DOI: http://dx.doi.org/10.22159/ajpcr.2017.v10i3.16569

\section{INTRODUCTION}

"Protein energy malnutrition" a major problem in the management of post-operative patients was long recognized by Hiram, an American surgeon way back in 1936, as he observed that weight loss was as significant predictor of surgical risk among his patients suffering from peptic ulcer disease [1]. According to "gut origin of sepsis" hypothesis the leaky gut is an essential factor in developing septic complications with the concept of bacterial translocation as demonstrated in vitro and in vivo studies [2]. In addition, nutritional depletion is associated with increased intestinal permeability and a decrease in villous height [3]. Post-operative nutritional supplementation has been known to improve the quality of life, nutritional status, and morbidity of patients [4]. Hence, "malnutrition matters" and "nutrition is the cutting edge in surgery [5]." Enteral nutrition has been known to bring about reduction in infectious complications in post major abdominal surgery [6]. Previous systematic reviews and meta-analysis have suggested that immune nutrition in critically ill have been associated with reduced hospital stay, infection rate, and inflammatory response [7]. Any catabolic stressful condition results in $50 \%$ loss of glutamine from the muscles and it is of utmost importance to deliver adequate amounts of glutamine to maintain the integrity of intestinal mucosa, to preserve the muscle glutamine pool and to improve overall nitrogen economy during conditions of stress [8]. Glutamine is known to be a precursor of protein synthesis and the mucosal and the immune cells in the body utilize this particular immunonutrient as an energy source in almost all the tissues. Furthermore, glutamine is involved in a large number of metabolic pathways. One of the major procedures which result in severe depletion of glutamine from the skeletal muscles, bringing about muscle loss immunosuppression thus resulting in increased risk for post-operative infection and sepsis is surgery. Various studies have indicated that glutamine supplementation in post-operative patients bring about improvement in their clinical outcome and also their intestinal permeability [9-12]. However, a conclusive data on this aspect have not been explored much in India. As noted in the review of Jan Wernerman, the recommendation from ESPEN and ASPEN/ SCCM is to add intravenous (IV) glutamine supplementation when total parenteral nutrition (TPN) is given to critically ill patients. In all guidelines, this is given a level A recommendation. Meta-analyses have identified a dose of $0.3-0.5 \mathrm{~g} / \mathrm{kg} / \mathrm{d}$ in parenteral nutrition to normalize plasma glutamine concentration in almost all critically ill patients. However, no sufficient data have been obtained on the enteral glutamine requirement in post-surgery patients. Hence, this study attempts to understand the effect of glutamine supplementation in patients following abdominal surgery on plasma glutamine levels, length of hospitalization $(\mathrm{LOH})$, and rate of infection.

\section{METHODS}

This was a randomized controlled trial wherein 30 participants following abdominal surgery belonging to the age group of 20-55 years were recruited from the surgery ward of ESIC hospital, Ayanavaram using purposive sampling technique. The patient characteristics are given in Table 1.

\section{Exclusion criteria}

Patients with comorbidities such as Type I diabetes and Type II diabetes on insulin management, renal diseases (creatinine concentration $>2.5 \mathrm{mg} / \mathrm{dl}$ ), cardiac disorders (Class III or IV), hepatic disease (total bilirubin concentration $>3 \mathrm{mg} / \mathrm{dl}$ ), autoimmune diseases, chronic use of steroids ( $30 \mathrm{mg}$ or more for more than a month), chronic obstructive pulmonary disease (partial pressure of carbon dioxide $>375 \mathrm{kPa}$ or $50 \mathrm{mmHg}$ ) and pregnant women.

Withdrawal criteria

Non-compliance with the blood test.

Ethical approval

The study was approved by the Independent Ethics Committee at Vels University, Chennai. 30 consenting participants were randomly 
assigned into two groups preoperatively namely: Control (diet) group and experimental (diet+supplement) group.

\section{Dietary management}

Gastrostomy and jejunostomy tubes were placed during the surgery for post-operative nutrition support. However, $10 \%$ of the participants were given oral feeds directly in post-surgery as they showed tolerance for the same. The nutrition formula of both the groups was closely matched for energy and protein content. Feeding for either group began at strength of $1200 \mathrm{kcal} /$ day further advancing it on a daily basis toward the goal caloric requirement of $35-40 \mathrm{kcal} / \mathrm{kg}$ body weight. Goal nutrition also provided $1.5 \mathrm{~g}$ protein/kg body weight/day. The experimental group was given 0.5 g glutamine/day for 5 days. Tube feeding tolerance for the participants on the same was done by daily recording of nausea, vomiting, or diarrhea.

\section{Glutamine supplement}

Meta gluta ZS glutamine granules were used in the study. Each sachet contained $10 \mathrm{~g}$ glutamine. The supplement was weighed as per the dosage requirement of $0.5 \mathrm{~g} / \mathrm{kg}$ body weight for each patient using a digital weighing scale.

\section{Route of administration}

The supplement was given in divided doses throughout the day. $10 \mathrm{~g}$ of the glutamine from the supplement (Meta gluta ZS) was mixed in $180 \mathrm{ml}$ of water and given orally and enterally for the patients where oral feed was not possible.

\section{Mode of study}

The study protocol was divided into 4 sections:

1. Post-operative day 1 assessment of plasma glutamine levels

2. The primary study period of 5 post-operative enteral feeding days

3. Reassessment of plasma glutamine levels on day 6 of feeding

4. Follow-up and tracking the incidence of infection and $\mathrm{LOH}$ till the patient was discharged.

\section{Statistical analysis}

Continuous data were summarized as mean \pm standard deviation. Independent t-test was used to compare the two groups with respect to body mass index, age, calories, and proteins received by day 5 and $\mathrm{LOH}$. The difference in incidence of infection between the two groups was analyzed using the Chi-square test and the differences in plasma glutamine levels on day 6 were analyzed using independent t-test. Paired t-test was used to compare the plasma glutamine levels within the group pre- and post-supplementation

\section{RESULTS AND DISCUSSION}

A total of 30 patients following abdominal surgery were recruited in this study and were randomly selected.

The patients were randomly divided into two groups, namely control and experimental groups. The participants mainly belonged to the lower socioeconomic class. Patient characteristics are listed in Table 1. The nutrition formulas of both the groups were closely matched for energy and protein content. Feeding for either group began at strength of $1200 \mathrm{kcal} /$ day further advancing it on a daily basis toward the goal caloric requirement of $35-40 \mathrm{kcal} / \mathrm{kg}$ body weight. Goal nutrition also provided 1.2-1.5 g protein $/ \mathrm{kg}$ body weight/day. The caloric and protein distribution achieved as on day 5 have been listed in Table 2. The surgical procedures followed by both the groups are given in Fig. 1.

\section{LOH}

The average LOH was $19.8 \pm 13.1$ days in the experimental group and $25.13 \pm 15.13$ days in the control group. The $\mathrm{LOH}$ with glutamine supplementation was significantly shortened in an experiment with a $\mathrm{p}=0.05$.

\section{Incidence of infection}

About $53.3 \%$ of the participants in the control group were reported to have secondary infection post-surgery as compared to only $26.66 \%$ in the experimental group as shown in Table 3. The differences in the rate of infection among the two groups were significantly different with a $\mathrm{p}<0.05$ as seen in Table 3 . Nutrition support has been widely used in the area of surgery, where the benefit on patients' prognosis is evident. Surgical site infections and wound and tissue dehiscence are well known post-operative complications in gastrointestinal surgery. Thus, an appropriate and feasible nutrition support strategy is necessary and beneficial for patients' prognosis. Several researchers have analyzed the role of glutamine post-surgery. Dechelotte et al. evaluated the absorption and metabolic effects of enterally administered glutamine using stable isotope methods in healthy subjects. Plasma glutamine showed a dose-dependent increase and they concluded that glutamine is effectively absorbed by the jejunum. A meta-analysis including 9 randomized, controlled clinical trials, with a total of 373 patients undergoing abdominal surgery, concluded that administration of parenteral nutrition supplemented with glutamine (20-40 g/day) has a beneficial effect on nitrogen balance, reduces hospital length of stay and infectious complications. Oguz conducted a study in post-operative patients with colorectal cancer, where enteral nutrition versus enteral nutrition supplemented with parenteral glutamine was administered, in a total of 109 patients, concluding that glutamine supplements reduce the number of post-operative complications and hospital stay.

Table 1: Characteristics of patients

\begin{tabular}{lll}
\hline Details & $\begin{array}{l}\text { Control } \\
\text { group (diet) }\end{array}$ & $\begin{array}{l}\text { Experimental } \\
\text { group (diet+supplement) }\end{array}$ \\
\hline Age & $38 \pm 13.45$ years & $39.4 \pm 12.33$ years \\
BMI & $23.3 \pm 6.76 \mathrm{~kg} / \mathrm{m}^{2}$ & $21.7 \pm 2.98 \mathrm{~kg} / \mathrm{m}^{2}$ \\
Male & 8 & 10 \\
Female & 7 & 5 \\
n (sample size) & 15 & 15 \\
\hline
\end{tabular}

BMI: Body mass index

Table 2: Mean calories and protein distribution in the two groups

\begin{tabular}{llll}
\hline Group & $\begin{array}{l}\text { Control } \\
\text { group (n=15) }\end{array}$ & $\begin{array}{l}\text { Experimental } \\
\text { group (n=15) }\end{array}$ & t-value \\
\hline $\begin{array}{l}\text { Mean } \\
\text { calories (kcal) }\end{array}$ & $1602 \pm 296.70$ & $1585.33 \pm 236.57$ & $0.042 \mathrm{NS}$ \\
Mean protein (g/d) & $65.26 \pm 10.25$ & $61.93 \pm 14.39$ & $0.223 \mathrm{NS}$ \\
\hline NS: Not significant & & &
\end{tabular}

Table 3: Hospitalization and incidence of infection in control versus experimental group

\begin{tabular}{lllll}
\hline Group & LOS (days) & t-value & $\begin{array}{l}\text { Incidence of } \\
\text { infection (\%) }\end{array}$ & $\chi^{2}$-value \\
\hline $\begin{array}{l}\text { Control } \\
\text { group (n=15) }\end{array}$ & $25.13 \pm 15.13$ & $1.024^{*}$ & 53.30 & $2.36^{*}$ \\
$\begin{array}{l}\text { Experimental } \\
\text { group (n=15) }\end{array}$ & $19.8 \pm 13.1$ & & 26.60 & \\
\hline
\end{tabular}

*Significant at 5\% level. LOH: Length of hospitalization

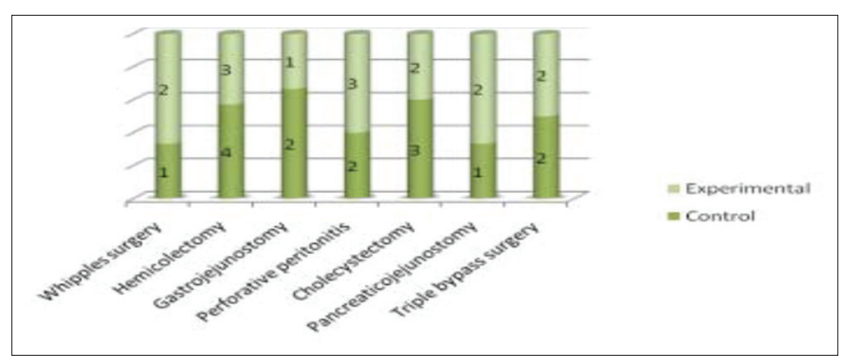

Fig. 1: Types of surgery in two groups 
Kumar compared in patients with peritonitis and abdominal injuries the administration of enteral glutamine ( $45 \mathrm{~g} /$ day) versus conventional EN without finding benefits in the glutamine group. Jan Wernerman mentioned that in post-operative patients, a daily IV glutamine dose of $20 \mathrm{~g}$ attenuates the decrease otherwise seen in skeletal muscle. This dose was originally chosen from a calculation of the decline in the free glutamine pool. Researchers in the ASPEN position paper on parenteral nutrition for glutamine supplementation have stated the probability of parenteral nutrition glutamine supplementation being better over enteral administration of glutamine in surgical and critically ill patients. However, parenteral nutrition generally proves to be very expensive and is not affordable for the lower socioeconomic group. Hence keeping this in mind in this study, oral glutamine supplements were used at a dosage of $0.5 \mathrm{~g} / \mathrm{kg}$ body weight for a period of 5 days and it was observed that plasma glutamine levels on day 6 of feeding showed a significant increase as compared to day 0 in both the groups.

Proteins 1.2-1.5 g protein $/ \mathrm{kg}$ body weight was supplied through the diet as protein consumption also has a direct correlation with the glutamine levels. However as shown in Table 3, the increment was significantly more in the experimental group as compared to the control group. Similar finding was observed in a study done on patients receiving IV glutamine supplementation following elective abdominal surgery. The incidence of infection in the control group was found to be almost twice that in the experimental group (53.3\% vs. $26.6 \%)$ considering the role of glutamine in combating infection. Furthermore, the LOH was found to be significantly higher in the control group as compared to the experimental group $(25.13 \pm 15.13$ day's vs. $19.8 \pm 13.1$ days $)$. In this study, due to limitations in the size of the samples, a great significant value could not be obtained. A similar study done on burn patients in China displayed normalization of the plasma glutamine levels after oral glutamine supplementation $(0.5 \mathrm{~g} / \mathrm{kg}$ body weight) for 14 days.

\section{CONCLUSION}

Hence, the fact that glutamine does help in reducing the rate of infection cannot be denied. As observed in this study, the experimental group did far better than the control in terms of $\mathrm{LOH}$ and incidence of infection. However since no such guidelines for oral glutamine supplementation in patients following abdominal surgery is available, we need to confirm this finding with larger population groups.

\section{REFERENCES}

1. Hiram SO. Percentage of weight loss basic indicator of surgical risk in patients with chronic peptic ulcer. J Am Med Assoc 1936;106:458-60.

2. MacFie JO, Boyle C, Mitchell CJ, Buckley PM, Johnstone D, Sudworth P. Gut origin of sepsis: A prospective study investigating associations between bacterial translocation, gastric microflora and septic morbidity. Gut 1999;45:223-8.

3. van der Hulst RR, von Meyenfeldt MF, van Kreel BK, Thunnissen FB, Brummer RJ, Arends JW, et al. Gut permeability, intestinal morphology, and nutritional depletion. Nutrition 1998;14:1-6.

4. Beattie AH, Prach AT, Baxter JP, Pennington CR. A randomized controlled trial evaluating the use of enteral nutritional supplements postoperatively in malnourished surgical patients. Gut 2000;46:813-8.

5. Kratzing C. Pre-operative nutrition and carbohydrate loading. Proc Nutr Soc 2011;70:311-5.

6. Beier-Holgersen R, Boesby $\mathrm{S}$. Influence of postoperative enteral nutrition on postsurgical infections. Gut 1996;39:833-5.

7. Sodergren MH, Jethwa P, Kumar S, Duncan HD, John T, Pearce CB, Immuno nutrition in patients undergoing major upper gastrointestinal surgery: A prospective double-blind randomized controlled study. Scand J Surg 2010;99:153-61.

8. Fürst, P, Stehle P. Glutamine supplemented nutrition in clinical practice and use of glutamine-containing dipeptides. Infusionsther Transfusionsmed 1995;22:317-24.

9. Morlion BJ, Stehle P, Wachtler P, Köller M, König W, Fürst P, et al. Total parenteral nutrition with glutamine dipeptide after major abdominal surgery: A randomized, double-blind, controlled study. Ann Surg 1998;227:302-8.

10. Lin MT, Kung SP, Yeh SL, Liaw KY, Wang MY, Kuo ML, et al. Glutamine-supplemented total parenteral nutrition attenuates plasma interleukin-6 in surgical patients with lower disease severity. World J. Gastroenterol 2005;11:6197-201.

11. Ward N. Nutrition support to patients undergoing gastrointestinal surgery. Nutr J 2003;2:18.

12. Jian ZM, Cao JD, Zhu XG, Zhao WX, Yu JC, Ma EL, et al. The impact of alanyl-glutamine on clinical safety, nitrogen balance, intestinal permeability, and clinical outcome in postoperative patients: A randomized, double-blind, controlled study of 120 patients. J Parenter Enteral Nutr 1999;23:S62-6. 